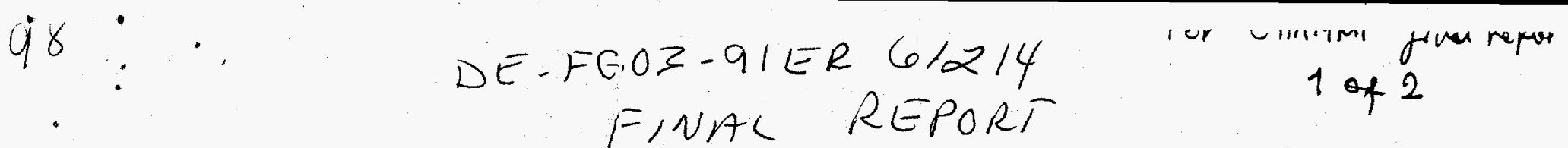

\title{
Development of an Atmospheric Model Based on a Generalized Vertical Coordinate
}

\author{
Akio Arakawa (PI) and Celal S. Konor \\ University of California, Los Angeles
}

Project Start Date: 09/12/91, Project End Date: 08/31/97

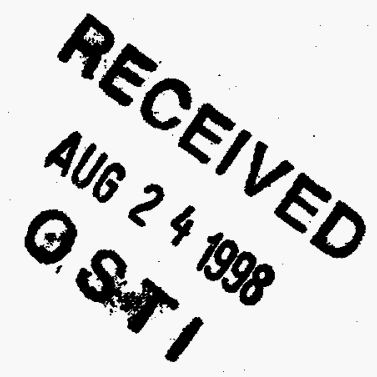

\section{Introduction}

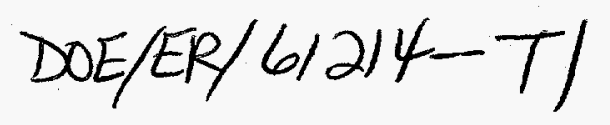

There are great conceptual advantages in the use of an isentropic vertical coordinate in atmospheric models. Design of such a model, however, requires to overcome computational problems due to intersection of coordinate surfaces with the earth's surface. Under this project, we have completed the development of a model based on a generalized vertical coordinate, $\zeta=F\left(\theta, p, p_{s}\right)$, in which an isentropic coordinate can be combined with a terrain-following $\sigma$ coordinate a smooth transition brtween the two.

One of the key issues in cleveloping such a model is to satisfy the consistency between the predictions of pressure and potential temperature. In our model, the consistency is satisfied by the use of an equation that determines the vertical mass flux. A procedure to properly choose $\zeta=F\left(\theta, p, p_{s}\right)$ is also developed, which guarantees that $\zeta$ is a monotonic function of height even when unstable stratification occurs. The design of the generalized vertical coordinate model is presented by Konor and Arakawa (1997).

There are two versions of the model constructed in parallel: one is the middle-latitude $\beta$ plane version and the other is the global version. Both of these versions include moisture prediction, relaxed large-scale condensation and relaxed moist-convective adjustment schemes. A well-mixed planetary boundary layer $(\mathrm{PBL})$ is also added.

In section 2, we will briefly describe the model and discuss the rationale behind its key formulations. In section 3 , we wrill discuss simulations obtained by using the two versions. In section 4 , we present a summary of the completed tasks and our future plans.

\section{Description of the model}

\section{a. The vertical grid}

The basic prognostic variables of the generalized vertical coordinate model for the free atmosphere are the horizontal velocity, pressure and potential temperature. The pressure $p$ is predicted by the mass continuily equation combined with the hydrostatic equation, while the 


\section{DISCLAIMER}

This report was prepared as an account of work sponsored by an agency of the United States Government. Neither the United States Government nor any agency thereof, nor any of their employees, makes any warranty, express or implied, or assumes any legal liability or responsibility for the accuracy, completeness, or usefulness of any information, apparatus, product, or process disclosed, or represents that its use would not infringe privately owned rights. Reference herein to any specific commercial product, process, or service by trade name, trademark, manufacturer, or otherwise does not necessarily constitute or imply its endorsement, recommendation, or favoring by the United States Government or any agency thereof. The views and opinions of authors expressed herein do not necessarily state or reflect those of the United States Government or any agency thereof. 


\section{DISCLAIMER}

Portions of this document may be illegible electronic image products. Images are produced from the best available original document. 
potential temperature $\theta$ is predicted by the thermodynamic energy equation. When $\zeta=p$, the prognostic equation for $p$ is automatically satisfied. When $\zeta=\theta$, on the other hand, the prognostic equation for $\theta$ is automatically satisfied under adiabatic processes. In the lowest layer of the model, which is designated for planetary boundary layer, the vertically mixed horizontal velocity $\mathbf{v}_{M}$ and potential tempesature $\theta_{M}$ are predicted. The mixed layer depth $z_{B}$ is also predicted by mass continuity equation applied to the PBL.

The vertical grid of the model is chosen in view of the convenience for maintaining the consistency described above (see Fig. 1). In the grid above PBL, the horizontal velocity $\mathbf{v}$ is predicted for each of the model layers. At the levels separating these layers, both $p$ and $\theta$ are predicted and the vertical mass flux is diagnosed. When $\zeta=p$ or $\sigma$, the grid becomes the Charney-Phillips grid, which ha:s important advantages over the Lorenz grid (Arakawa and Konor, 1996). We predict the water vapor mixing ratio $q$ at the same levels as $\theta$.

\section{b. The vertical mass flux equation}

The consistency between the predictions of the pressure and the potential temperature is maintained by requiring

$$
0=\left(\frac{\partial}{\partial t}\right)_{\zeta} F\left(\theta, p, p_{s}\right)
$$

Using the thermodynamic equation, the pressure tendency equation and the surface pressure tendency equation in (1), the vertical mass flux equation can be obtained.

For the time discrete case?, the vertical mass flux equation is solved through a two-step procedure. In the first step, deviation of $\zeta=F\left(\theta, p, p_{s}\right)$ from its original value is determined by solely considering the horizontal advection of the potential temperature and diabatic heating in the thermodynamic equation and the convergence of horizontal mass fluxes in the continuity equation. In the second step, usirig an iteration procedure, the vertical mass flux is determined to compensate this deviation of $\zeta$ through the vertical advection of the potential temperature and the vertical convergence of the vertical mass flux. Doing so guaranties that $\zeta$ of a coordinate surface remains unchanged.

\section{c. The choice of $\zeta=F\left(\theta, p, p_{s}\right)$}

The primary purpose for using this coordinate is to combine the advantages of the isentropic coordinate away from the surface with the advantages of the standard $\sigma$-coordinate near the surface. Assuming that $\sigma \equiv \sigma\left(p, p_{s}\right)$ monotonically increases with height, a hybrid $\sigma-\theta$ vertical 
coordinate must satisfy the following requirements:

$$
\partial \zeta / \partial \sigma>0
$$

with $\zeta=$ const. and $\zeta=\theta$ at the lower and upper boundaries, respectively. These requirements can be satisfied by defining

$$
\zeta \equiv f(\sigma)+g(\sigma) \theta
$$

with $g(\sigma)=0$ at the lower boundary, $g(\sigma)=I$ and $f(\sigma)=0$ at the upper boundary, and

$$
\frac{\partial f}{\partial \sigma}+\frac{\partial g}{\partial \sigma} \theta_{\min }+\left(\frac{\partial \theta}{\partial \sigma}\right)_{\min } g=0
$$

Here $g$ and $d g / d \sigma$ are assumed to be positive andmin denotes prescribed lower bound. Now we can define $\zeta$ using (3) by first choosing a proper $g(\sigma)$ in (4) and then integrating that equation with respect to $\sigma$ to obtain $f(\sigma)$. We are currently using $g(\sigma) \equiv g_{o}\left(1-e^{-\alpha \sigma}\right)$, with $\sigma \equiv\left(p_{S}-p\right) /\left(p_{S}-p_{T}\right)$, where $g_{o}$ and $\alpha$ are constants and $p_{T}$ is the constant pressure at the upper boundary. $\zeta$ obtained following the above procedure is always a monotonic function of height even when unstable stratification occurs.

\section{Numerical simulations with the model}

The performance of the generalized vertical coordinate model has been tested by simulating the nonlinear evolution of midlatitude disturbances on a $\beta$-plane. We have performed several simulations using different vertical and horizontal resolutions and physical parameters. In these simulations, no moist processes are included; instead a weak Newtonian heating is included to restore the thermal field to the zonally-symmetric initial basic state. The initial conditions consist of a zonally uniform geostrophically balanced basic state and a smallamplitude random perturbation of potential temperature and pressure superimposed on the basic state. An example from these sinulations is presented in Konor and Arakawa (1997). Analyses of the simulated fields reveal that the model captures the details of surface and upper-level frontogenesis without serious computational difficulties. We are currently testing the performance of the global version including moisture prediction, relaxed large-scale condensation and moist-convective adjustment schemes. This version also includes a parameterized PBL. 
4. A summary of the completed and future tasks

The development of a model based on a generalized vertical coordinate is underway. The "dynamics" portion of the model has been completed and successfully tested (see Konor and Arakawa, 1997). The global version of this model is now under development. Significant progress has been made towards a global version of the model with comprehensive physical processes. The latest version of the model includes moisture prediction, large-scale condensation and moist-convective adjustment schemes. To parameterize the PBL processes, a well-mixed layer is added to the model near the surface. We are currently working on details of PBL parameterization, which is based on the prognostic turbulence kinetic energy and variances. The final decision on the cumulus parameterization scheme has not been made yet. Among the possibilities, we are considering an empirical cumulus parameterization and a relaxed Arakawa-

Schubert cumulus parameterization. Shortwave and longwave radiation schemes will be included in the model.

\section{Publications supported by DOE GRANT \# DE-FG03-91ER61214 A003 (CHAMMP)}

Konor, C. S., C. R. Mechoso and A. Arakawa, 1994: Comparison of frontogenesis simulations with $\theta$ and $\sigma$ vertical coord nates and design of a general vertical coordinate model. International Symposium on Extratropical Cyclones, 27 June-1 July 1994, Bergen, Norway.

Arakawa, A. and C. S. Konor, 1994: Comparison of atmospheric models based on the Lorenz and Charney-Phillips grids. International Symposium on Extratropical Cyclones, 27 June-1 July 1994, Bergen, Norway.

Arakawa, A. and C. S. Konor anc: C. R. Mechoso, 1994: A generalized vertical coordinate and the choice of vertical grid for atmospheric models. Tenth conference on Numerical Weather Prediction, July, 18-22, 1994, Portland, Oregon.

Arakawa, A. and C. S. Konor, 1996: Vertical differencing of the primitive equations based on a Charney-Phillips type grid in a $\sigma-p$ hybrid vertical coordinates. Mon. Wea. Rev. 124, 511528.

Konor, C. S. and A. Arakawa, 1997: Vertical differencing of the primitive equations based on a generalized vertical coordinate. Mon. Wea. Rev. accepted.

Konor, C. S. and A. Arakawa, 1996: A generalized vertical coordinate and the choice of vertical grid for atmospheric models. Eleventh conference on Numerical Weather Prediction, August, 19-23, 1996, Norfolk, Virginia. 


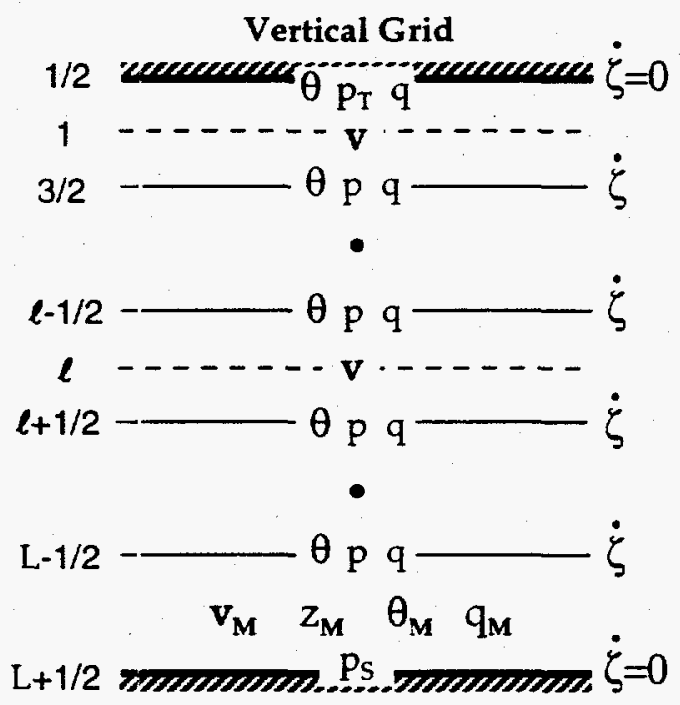

Fig. 1 


\title{
Development: of an Advanced Finite-Difference Atmospheric General Circulation Model
}

\author{
Akio Arakawa (PI) and Carlos R. Mechoso (PI) \\ University of California, Los Angeles \\ Project Start Date: 09/12/91, Project End Date: 08/31/97
}

\section{Objectives}

The goal of this project is to further develop an advanced finite-difference atmospheric climate model for better performance of the simulations of the seasonal cycle and interannual variability of Earth's climate. The simulations will be performed with sea surface temperatures (SST) either prescribed (uncoupled mode) or produced by a coupled oceanic general circulation model (coupled mode). Additional objectives include the upgrading of the model's code for high-performance computing.

\section{Accomplishments}

We have achieved significant accomplishments in all objectives targeted under this project. In summary, the key components of the UCLA atmospheric general circulation model (AGCM) have been thoroughly revised and the overall model performance has been greatly improved. The model has been coupled to the Princeton/University Modular Ocean Model (MOM), multi-decadal runs have been completed, and several physical aspects crucial to the behavior of the coupled-atmosphere ocean system have been identified. The model code has been parallelized for massively parallel processors, which has allowed to double the resolution of the standard version that has a performance of almost 10 Gflops. We have maintained a close collaboration with CHAMMP researchers at the Lawrence Livermore National Laboratory (LLNL), and kept them updated on model upgrades. We have also exchanged code components as well as scientific findings witlı CHAMMP researchers at Colorado State University (CSU). Significant progress has been made towards a new model version based on a generalized vertical coordinate.

This report presents highlights of our accomplishments in the categories of 1) model development, 2) code developmerit, and 3) better understanding of selected climate phenomena. The work on development of the generalized vertical coordinate model is described in a separate paper of this volume.

1) Model Development 
We have developed a scheme to represent the effect of resonant nonhydrostatic waves on the lee side of mountains associated with generation of a nonlinear critical level. The scheme is now a standard model comple:nent, and has contributed significantly to the more realistic simulation of zonal mean flow, sea-level pressure, etc. A substantial effort was also dedicated to revisions of the PBL parameterization which improved the simulated surface fluxes as well as stratus clouds.

We explored several key issues relevant to the performance of the troposphericstratospheric version of UCLA AGCM in simulating the stratospheric zonal mean flow. The parameterization of photochemical processes used in the model had a tendency to underestimate the ozone mixing ratios, and to froduce substantial biases in zonally-averaged temperatures and winds, as well as errors in planetary wave amplitudes and phases. Those deficiencies were largely alleviated by prescribing ozone mixing ratios from observed climatologies and incorporating a more accurate formulation of shortwave radiation absorption by ozone.

There was significant progress in the development of a prediction scheme for cloud liquid water and cloud ice based on a five-phase bulk microphysics. Our starting point was a methodology for predicting licquid and ice phases separately as developed at UCLA. The proposed work aimed to extend and refine previous work with emphasis on the parameterization of the effects of microphysical processes on the large-scale flow. Preliminary results of simulations with a model version that includes this scheme are very encouraging.

2) Efforts in Code Development in collaboration with LLNL; NASA/JPL; NASA/HPCC)

There are two mine components in the AGCM. One is AGCM/Dynamics, which computes the evolution of the fluid flow governed by the primitive-equations. In an MPP, AGCM/Dynamics requires two types of interprocessor communications: 1) message exchanges among neighboring processors in the finite difference component, and 2) non-nearest neighbor exchanges in the spectral filtering component, which is performed only in polar regions. The other component is AGCM/Physics, which computes the effect of processes not resolved by the model's grid on processes that are resolved by the model's grid. The AGCM/Physics computational load varies in both space and time as elements such as cloud distribution and conditional instability of the atmosphere change. We have implemented a static load redistribution algorithm to load. balance the filtering step, and a quasi-dynamic scheme to load balance the AGCM/Physics (Lou and Farrara, 1996). We have also performed a number of single node optimizations to increase the per-node performance on the CRAY T3D.

The AGCM now boasts an overall parallel efficiency of $50 \%$ on 256 nodes of the CRAY 
T3D. This efficiency is very high for an atmospheric model code because the surface-to-volume ratio for these models is rather high and there are inherent load imbalances present. The execution rate is nearly 10 Gflops on 512 nodes of the CRAY T3D. The AGCM running side-byside with the Parallel Ocean Program (POP) can currently achieve a performance of 10.65 GFLOPS when 324 nodes are assigned to the AGCM and 188 nodes to the oceanic general circulation model (OGCM).

We have also developed an Earth System Model Information System (ESMDIS). This is a web-based database applications that has the following functions: 1) Sets up model runs, 2) Loads model output into database, 3) Browses metadata information, 4) Retrieves datasets, 5) Analyzes and validates model output, 6) Visualizes datasets.

3) Achievements in Climate Simulation

Simulations with the uncoupled AGCM demonstrate that the magnitude of surface evaporation can be affected by the optical properties of high-clouds through interactions between cloud, radiation and dynamical processes. A similar set of simulations with the coupled GCM show that increasing the emissivity of high clouds results in warmer SSTs. These experiments confirm that the atmosphere-oceian system can be extremely sensitive to the radiative effects of clouds.

The impact of Peruvian stratus clouds on the simulation of the tropical Pacific climate is a major concern in models that attempt to simulate and predict phenomena such as El NiñoSouthern Oscillation and its worldwide effects. We performed studies aiming to assess this impact. Our results demonstrate that Peruvian stratus cloud decks are crucial to the maintenance of the asymmetry about the equator of the eastern Pacific climate. Further, the seasonal cycle of these clouds plays an important role in producing the asymmetric features of the annual cycle of the cold tongue in sea surface temiperature at the equator.

We are currently performing and analyzing multi-decadal AGCM simulations at different resolutions, and have started preparations for a simulation with the $2.5^{\circ}$ lon $\times 2^{\circ}$ lat $\times 29$ layer of the $A G C M$ coupled to the $1 / 6^{\circ}$ lon $\times 1 / 6^{\circ}$ lat $\times 60$ layer Atlantic version of POP using the CRAY T3D/T3E.

Publications supported by DOE GRANT \#DE-FG03-91ER61214 A003 (CHAMMP)

1. Wehner, M. F., J. J. Ambrosiario, J. C. Brown, W. P. Dannevick, P. G. Elgroth, A. A. Mirin, J. D. Farrara, C. -C. Ma, C. R. Mechoso, J. A. Spahr, 1993: Toward a high performance distributed memory climate model. International Symp. High Performance Distributed Computing (HPDC- 
2). Spokane, Washington, IEEE Computer Society. In press.

2. Ma, C. -C., C. R. Mechoso, A. Arakawa and J. D. Farrara, 1994: Sensitivity of a coupled oceanatmosphere model to physical parameterizations. J. Climate, 7, 1883-1896.

3. Mechoso, C. R., C. -C. Ma, J. D. Farrara and J. A. Spahr, 1994: Climate studies using a coupled atmosphere-ocean several circulation model. Research activities in Atmospheric and Oceanic Modeling. World Climate Research Programme, Reprint No. 17, G. J. Boer, Ed., 9.12-9.13.

4. Arakawa, A., C. S. Konor, and C. R. Mechoso, 1994: A generalized vertical coordinate and the choice of vertical grid for atmospheric models. Tenth Conference on Numerical Weather Prediction, 17-22 July, Portland, Dregon.

5. Ma, C. -C., C. R. Mechoso, and A. Arakawa, 1994: Effect of physical parameterizations on the performance of a coupled oceari-atmosphere GCM. Proceedings of the Conference on Weather Analysis and Forecasting, Taipei, Taiwan, Nov. 24-26.

6. Yu, J. -Y., C. R. Mechoso, and C. -C. Ma, 1994: The UCLA coupled atmosphere-ocean GCM simulation of the surface heat flux in the Tropical Pacific. Proceedings of the Conference on Weather Analysis and Forecastirig, Taipei, Taiwan, Nov. 24-26.

7. Konor, C. S., C. R. Mechoso, and A. Arakawa, 1994: Comparison of frontogenesis simulations with isentropic and normalized pressure vertical coordinates. International Symposium on the Life Cycles of Extratropical Cyclones. June 27-July 1, Bergen, Norway.

8. Halpern, D., Y. Chao, C. -C Ma and C. R. Mechoso, 1995: Comparison of tropical Pacific temperatures and current simulations with two vertical mixing schemes embedded in an ocean general circulation model and reference to observations. J. Geophys. Res., 100, 2515-2522.

9. Ma, C. -C., C. R. Mechoso, A. Robertson, and A. Arakawa, 1996: Peruvian stratus clouds and the tropical Pacific circulation - a. coupled ocean-atmosphere GCM study. J. Climate. Submitted.

10. Yu, J. -Y., and C. R. Mechoso, 1996: Relationships between surface heat flux and SST in the tropical Pacific. Dynamics of Atmosphere and Oceans, Special Issue. Submitted.

11. Kim, Young-Joon, C. R. Mechoso, and A. Arakawa, 1996: Impact of gravity-wave drag and envelope orography on climate simulated by a general circulation model. 11th Conference on Numerical Weather Prediction, 19-23 August. 1996, Norfolk, VA, AMS. 10 B.1.

12. Mechoso, C. R., S. G. Philander, C. -C. Ma, and J. -J Yu, 1996: Modelling of the eastern tropical Pacific climate. 8th Conference on Air-Sea Interaction and Symposium on GOALS, 28 January-2 February 1996, Atlanta, GA, AMS.

13. Ma, C. -C., J. -Y. Yu, C. R. Mechoso, and A. Arakawa, 1996: New aspects of the UCLA coupled GCM - global ocean circulation and improved cloud representations. 7 th Conference on Climate Variations, 2-7 February 1997, Long Beach, CA, AMS. 
(Follow instructions on the back)

7. FEDERAL AGENCY AND ORGANIZATIONAL ELEMENT 70 WHICH
REPORT IS SUBMITTED
USDOE OAKLAND OPERATIONS OFFICE
3. RECIPIENT ORGANIZATION (Name and complete addresis, including ZIP code)
THE REGENTS OF THE UNIVERSITY OF CALIFORINIA
UNIVERSITY OF CALIFORNIA, LOS ANGELES
10920 Wilshire BIVd., 5th Floor, Suite 500
LOS ANGELES, CA 90095

8. PROJECT PERIOD (see instructions)

\begin{tabular}{c|c}
\hline FROM (Month, day, year) & $\begin{array}{c}\text { To (Month, day, year) } \\
08 / 31 / 97\end{array}$ \\
\hline
\end{tabular}

10. STATUS OF FUNDS

a. Net outlays previously reported

b. Total outlays this report period

c. Less: Program income credits

d. Net outlays this report period (Line $b$ minus line $c$ )

2. FEDERAL GRANT OR OTHER
IDENTIFYING NUMBER

OMB Approved

No. $80-R 0180$

DE-FG03-91-ER61214

4. EMPLOYER INDENTIFICATION NUMBER

1-956006143-A1

5. RECIPIENT ACCOUNT NUMBER OR IDENTIFYING NO.

\begin{tabular}{|c|c|}
\hline \multicolumn{2}{|c|}{22402} \\
\hline $\begin{array}{c}\text { 6. FINAL REPORT } \\
\text { XYes } \square \text { No }\end{array}$ & 7. BASIS \\
\hline
\end{tabular}

\Yes $\square$ No $\square$ Cash $邓$ Accrual

9. PERIOD COVERED BY THIS REPORT

e. Net outlays to date (Line a plus line d)

\begin{tabular}{|l|l}
\hline FROM (Month, day, year) & TO (Month, day, year)
\end{tabular} $11 / 15 / 96$ $08 / 31 / 97$

f. Less: Non-Federal share of outlays

RECEYYE

\begin{tabular}{|c|} 
RECETEQ \\
DEC 181997 \\
\hline SPOASOAEORESEAPG
\end{tabular}

$\$$

$815,398.25$

$179,330.75$

g. Total Federal share of outlays (Line e minus line $f$ )

$994,729.00$

h. Total unliquidated obligations

i. Less: Non-Federal share of unliquidated obligations shown in line $h$ 0.00

$j$. Federal share of unliquidated obligations (Line $h$ minus line i) 0.00

k. Total Federal share of outlays and unliquidated obligations (Line $\mathrm{g}$ plus line j)

994.729 .00

I. Total cumulative amount of Federal funds authorized

994.729 .00

m. Unobligated balance of Federal funds (Line | minus line $k$ )

\begin{tabular}{|c|c|c|c|c|c|}
\hline \multirow{2}{*}{$\begin{array}{l}11 . \\
\text { INDIRECT } \\
\text { EXPENSE }\end{array}$} & \multicolumn{2}{|c|}{$\begin{array}{l}\text { a. TYPE OF RATE } \\
\text { (Place " } X \text { " in appropriate box) }\end{array}$} & PRCIVISIONAL \PREDETERMINED & FINAL & FIXED \\
\hline & $\begin{array}{l}\text { b. RATE } \\
49.00 \%\end{array}$ & $\begin{array}{l}\text { c. BASE } \\
\$ 118,940.97\end{array}$ & $\begin{array}{c}\text { d. TOTAL AMOUNT } \\
\$ 58,281.08\end{array}$ & e. FEDEF & HARE \\
\hline
\end{tabular}

12. REMARKS : (Attach any explanations deemed necessary or inlormation required by Federal sponsoring agency in compliance with governing legislation.)

$\$ 58,281.08$

\footnotetext{
13. CERTIFICATION

1 certify to the best of my knowledge and belief that this report is correct and complete and that all outlays and unliquidated obligations are for purposes set forth in the award documents.
}

\begin{tabular}{ll}
\hline DISTRIBUTION: & Copy $1-$ Official Grant File \\
& Copy 2 - Grants Section, FAAB \\
& Copy 3 - Grantee
\end{tabular}

\begin{tabular}{|l|l|}
\hline SIGNATURE OF AUTHORIZED CERTIFYING OFFICIAL & DATE REPORT SUBMITTED \\
\hline $\begin{array}{l}\text { TYPED OR PRINTED NAMH OA TITLE } \\
\text { Karen I. Partipilo, Manager } \\
\text { Extramural Fund Management }\end{array}$ & $\begin{array}{c}\text { TELEPHONE (Area code, number } \\
\text { and extension) } \\
\text { (310)794-2844 }\end{array}$ \\
\hline
\end{tabular}

